The Training Package We delivered a 2 part training course to foster carers who wished to care for such infants. The aim of the training package was to equip carers with the knowledge and skills to safely care for such infants in the home environment.

Results Foster carers are now available to take infants with NAS home on pharmacological treatment as soon as stability is achieved. The quality of care delivered to such infants will improve significantly as a result. In addition cot occupancy will be reduced, vital at a time when demand for neonatal cots is extremely high.

\section{HUMANIZATION OF CARE IN ITALIAN PEDIATRICS UNITS: RESULTS OF A NATIONAL SURVEY}

doi:10.1136/archdischild-2012-302724.1730

'F Festini, ${ }^{2} \mathrm{P}$ Siani, ${ }^{3} \mathrm{~S}$ Bisogni, ${ }^{3} \mathrm{D}$ Ciofi. ${ }^{1} /$ talian Society of Pediatric Nursing Science - SISIP, Pistoia; ${ }^{2}$ Italian Cultural Association of Pediatricians, Neaples; ${ }^{3}$ University of Florence, Florence, Italy

Background Hospital admission is a stressful and fearful experience for children. Several kind of non clinical interventions have shown to be effective in improving the quality of life of children during hospital stay.

Goal To survey the interventions performed in Italian Pediatrics Unit to improve children's life during hospital stay.

Methods Cross-sectional study. The study was promoted by the Italian Cultural Association of Pediatricians (ACP) and by the Italian Society of Pediatric Nursing Science (SISIP). A 37-item online questionnaire was set up and an invitation to fill it in was sent by email using the two associations' mailing lists.

Results Questionnaires regarding 111 pediatrics units were returned, out of an extimated total of 724 Italian Pediatrics Units (PU) $(15.3 \%) .43 \%$ of PU have more than $50 \%$ of beds in 2 -bed rooms. In $90.1 \%$ of $\mathrm{PU}$ walls are multicoloured or decorated with paintings. A school is available only in $47.7 \%$ PU. A "toy library" or playroom is present in $66.7 \%$ PU. Outdoors playgrounds are available in $37.8 \%$ PU. Reading aloud to children is performed in $29.7 \%$ PU, activities with animals in $13.5 \%$. Play Volunteers operate in $80.2 \%$ of PU, Clown Doctors in $67.6 \%$. In PU with more than 1500 admissions per year, single rooms and a playroom is present more frequently than in others ( $\mathrm{p} 0.02$ and $\mathrm{p} 0.03$ respectively).

Discussion Although several non clinical interventions are available to reduce distress and anxiety in hospitalised children and to improve their quality of life, their diffusion in Italian Hospital still seems limited.

\section{THE ULSM CHILDREN ROUND-TRIP CARE: A SUCCESSFUL EXPERIENCE IN THE CONTINUITY OF CARE}

doi:10.1136/archdischild-2012-302724.1731

'CS Santos, 'TM Fernandes, ${ }^{2} \mathrm{AC}$ Barros. 'Unidade de Saude Familiar Infesta; 2Departamento da Mulher, da Criança e do Jovem, Unidade Local de Saúde de Matosinhos, EPE, Matosinhos, Portugal

Background Being able to identify early health changes before they manifest in everyday life, allows to correct them immediately and to prevent progress to irreversible stages (Oom, 2008). In this context, accessing and sharing information between different health care institutions and their professionals is an asset for the child and allows improving quality in care.

Aims and Method We aim to describe how is the information access and sharing in Matosinhos Local Health Care Unit (ULSM) and highlight their importance through a literature review.

Results The ULSM has two networked applications in support for nursing teams and medical teams that allow them to share information. There are also manuals of coordination between different services including primary care and hospital care. Concerning primary care, in the specific case of the Family Health Unit Infesta, a joint manual resulting from a simple set of rules was established. It aims reducing bureaucracy, streamline and simplify referral procedures (Gonçalves et al, 2011), becoming clear and advantageous to the parties involved in the process.

Conclusions Access to patient clinical information is available 24/7 in all sectors of ULSM, allowing a contextualized and continuous monitoring, leading to higher quality health care for the child. The ability to use data in a useful way, allows reducing errors, enhancing patients and clinician communication, provides cost savings and improves quality in many areas across the full-spectrum of paediatric primary care (Adams \& Baucher, 2003; Simonian, 2007; Hinman \& Davidson, 2009).

\section{RISK PROPORTIONATE CLASSIFICATION BY A NATIONAL COMPETENT AUTHORITY TO REDUCE BARRIERS FOR CLINICAL TRIALS}

doi:10.1136/archdischild-2012-302724.1732

${ }^{1} \mathrm{H}$ Hill, ${ }^{2} \mathrm{E}$ Jacques-Aigrain, ' $\mathrm{M}$ Turner, TINN Treat Infection in Neonates. 'Women's and Children's Health, University of Liverpool, Liverpool, UK; ${ }^{2}$ Paediatric Pharmacology and Pharmacogenetics, Robert Debré Hopital, Paris, France

Background The UK MHRA has introduced a risk-proportionate approach to the approval and management of clinical trials of investigational medicinal products (CTIMP). The aim is to reduce the complexity of regulations and governance by identifying key hazards and promoting risk mitigation. Prospective risk management will reduce dependence on quality controls and monitoring during trials.

Methods A risk assessment template for neonatal CTIMPs was developed, based on the TINN Ciprofloxacin Pharmacokinetic Trial. The study was compared to standard medical care, an analysis of study design was undertaken to ensure the protection of participants' rights and data reliability. The tool was moderated by experts in regulations and clinical trials.

Results The trial was classified as low-risk (Type A) from an IMP perspective. This allows reduced regulatory monitoring and IMP management. Ciprofloxacin is administered off label and involves vulnerable participants. The evidence required to mitigate this included the fact that the drug is administered as standard clinical care, there is published use of Ciprofloxacin for neonates and national prescribing guidelines.

4 key risk areas were identified: 1) patient safety/rights 2) reliability of results 3) research sites 4) governance. To mitigate the risks during trial conduct and the collection of data required specific neonatal trial management tools, training, standard operating procedures and systems for cross checking data.

Conclusion Neonatal CTIMPs are not always high risk. Regulations and inspections need to be proportionate to the risks arising from the trial-specific interventions and procedures. Risks can be mitigated by bespoke neonatal trial design.

\section{ACCEPTABILITY AND IMPLEMENTATION OF FIMNCI BY MEDICAL OFFICERS AND STAFF NURSES IN GOVERNMENT HEALTH INSTITUTIONS OF WESTERN INDIA}

doi:10.1136/archdischild-2012-302724.1733

'DV Patel, 1.2SM Nimbalkar, ${ }^{3} \mathrm{US}$ Singh, 'NM Kharod. 'Department of Pediatrics, Pramukhswami Medical College; ${ }^{2}$ Central Research Services, Charutar Arogya Mandal, Anand; ${ }^{3}$ Department of Community Medicine, Pramukhswami Medical College, India, India

Background and Aims FIMNCI (Facility based Integrated Management of Neonatal and Childhood Illnesses) course has been launched by Government of India to train Medical Officers (MOs) and Staff Nurses (SNs) of Government Institutions from year 2010 onwards. FIMNCI deals with intensive care of serious illnesses in 